\title{
Effect of oversize in wire-screen matrix to the matrix-holding tube on regenerator thermal performance
}

\author{
Ping-Hei Chen, Zei-Chi Chang and B.-J. Huang \\ Department of Mechanical Engineering, National Taiwan University, Taipei 10764, \\ Taiwan
}

Received 25 September 1995

\begin{abstract}
A typical regenerator in a cryocooler is usually made by packing hundreds of finemesh but oversize wire screens into a small circular tube to provide better thermal performance. By the use of the oversize wire screens, the flow leakage around the inner circumference of the tube is significantly reduced. The oversize in the wire screen is the difference between the diameter of the wire screen and the inner diameter of the tube. In the present study a single-blow test method was used to investigate the effect of oversize on the thermal performance of regenerators. Heat transfer and pressure measurements were performed on three test regenerators. The value in oversize ranged from $0.05 \mathrm{~mm}$ to $0.55 \mathrm{~mm}$. The average heat transfer rate of regenerators increases with oversize of wire screens. In addition, empirical relations are provided for the Nusselt number and friction factor versus the Reynolds number for each test regenerator.
\end{abstract}

Keywords: regenerators; heat transfer measurements; cryocoolers

\begin{tabular}{|c|c|c|c|}
\hline \multicolumn{2}{|c|}{ Nomenclature } & $\cdot \mathrm{NTU}_{\mathrm{w}}$ & Number of transfer unit of side wall, as \\
\hline$A_{\mathrm{HT}}$ & Heat transfer area of screen-packed matrix & $\mathrm{Nu}$ & Nusselt number, as defined in Equation (12) \\
\hline$A_{\mathrm{f}}$ & Frontal area of screen-packed matrix & $p$ & Dimensionless pressure of fluid flow \\
\hline$\Lambda_{\mathrm{w}}$ & Heat transfer area of external side wall & $R$ & Ratio of $\mathrm{NTU}_{\mathrm{w}}$ to $\mathrm{NTU}_{\mathrm{m}}$ \\
\hline$C_{p}$ & Fluid specific heat at constant pressure & $\operatorname{Re}$ & Reynolds number, as defined in Equation (10) \\
\hline$C_{\mathrm{m}}$ & Specific heat of screen-packed matrix & $R_{\mathrm{tc}}$ & Thermal capacitance ratio of screen-packed \\
\hline$C_{\mathrm{w}}$ & Specific heat of the side wall & & matrix to external tube wall, as defined in \\
\hline$d_{\mathrm{h}}$ & $\begin{array}{l}\text { Hydraulic diameter, as defined in Equation } \\
\text { (8) }\end{array}$ & $S_{\max }$ & $\begin{array}{l}\text { Equation (4) } \\
\text { Maximum slope of dimensionless exit fluid }\end{array}$ \\
\hline$d_{\mathrm{w}}$ & Wire diameter of wire-screen & & temperature $\mathrm{T}$ \\
\hline$f$ & Friction factor, as defined in Equation (11) & $T$ & Dimensionless temperature \\
\hline$h$ & $\begin{array}{l}\text { Average heat transfer coefficient of the } \\
\text { screen-packed matrix }\end{array}$ & $T_{\mathrm{f}}$ & $\begin{array}{l}\text { Dimensionless temperature of fluid flow as } \\
\text { defincd in Equation (12) }\end{array}$ \\
\hline$h_{\mathrm{w}}$ & $\begin{array}{l}\text { Average heat transfer coefficient of the side } \\
\text { wall }\end{array}$ & $T_{\text {fmax }}$ & $\begin{array}{l}\text { Dimensionless heated inlet temperature at the } \\
\text { steady state }\end{array}$ \\
\hline JTC & $\begin{array}{l}\text { Dimensionless Joule-Thomson coefficient, as } \\
\text { defined in Equation (4) }\end{array}$ & $T_{\mathrm{m}}$ & $\begin{array}{l}\text { Dimensionless temperature of screen-packed } \\
\text { matrix }\end{array}$ \\
\hline$k_{\mathrm{f}}$ & Fluid conductivity & $T_{\mathrm{w}}$ & Dimensionless temperature of side wall \\
\hline$L$ & Length of screen-packed matrix & $T_{0}$ & Dimensionless inlet fluid temperature at $t=0$ \\
\hline$M_{\mathrm{m}}$ & Mass of screen-packed matrix & $t$ & Dimensionless time \\
\hline$M_{\mathrm{w}}$ & Mass of external side wall & $t^{*}{ }_{\mathrm{sys}}$ & Time scale, as defined in Equation (4) \\
\hline$\dot{m}_{\mathrm{t}}$ & Mass flow rate of fluid & $V_{0}$ & Volume of the regenerator \\
\hline & Number of nodes & $X$ & Dimensionless axial distance from the inlet of \\
\hline & $\begin{array}{l}\text { Number of transfer unit of screen-packed } \\
\text { matrix, as defined in Equation (4) }\end{array}$ & & screen-packed matrix \\
\hline
\end{tabular}


Greek letters

$\epsilon \quad$ Porosity of screen-packed matrix

$\mu \quad$ Dynamic viscosity of fluid

$\mu_{\mathrm{J}} \quad$ Joule-Thomson coefficent

$\phi \quad$ Shape factor in Equation (8)

$\rho \quad$ Fluid average density

One of the major methods to improve the thermal efficiency of cryocoolers is to increase the heat transfer performance of regenerators in cryocoolers. In practice, the regenerator is comprised of a circular tube stacked with oversize wire screens to seal off the leakage of working fluid through the inner circumference of the tube. It has been shown that mesh size and wire diameter affect the thermal performance of regenerators ${ }^{I-3}$. Jones ${ }^{4}$ further measured the velocity profiles of air flow through the wire-screen matrices. The measured velocity profiles at the exit of regenerator matrices are non-uniform, high in the annular regions and low but uniform in the central regions. The effect of inhomogeneity in velocity distributions on the friction loss and thermal performance of regenerator matrices was theoretically assessed by Jones ${ }^{4}$. A single-blow technique ${ }^{1,2}$ or a test facility using oscillating flow ${ }^{5}$ are commonly adopted to evaluate the pressure loss and heat transfer characteristics of regenerators. Both heat transfer and pressure loss data of regenerators are essential considerations for the design of cryocoolers with higher efficiency. Although regenerator heat transfer coefficients determined using test facilities with an oscillating flow are closer to actual operation conditions in cryocoolers than those determined using the single-blow technique, the actual difference in determined heat transfer rates is not very signficant ${ }^{5}$. The advantages in using the single-blow technique are its simple operation and the low cost of instrumentation. In addition, measured results can easily be compared with abundant experimental and analytical data which are available from numerous studies performed on compact heat exchangers ${ }^{6-9}$ using the same single-blow technique.

However, no prior studies have experimentally investigated the effect of the oversize in wire screen on the thermal performance of regenerators. Therefore, in this study the single-blow technique was used to measure the pressure loss and thermal performance of test regenerators with wire screens having different oversize values. For the test regenerators in this study, the oversize in wire screen ranges from $0.05 \mathrm{~mm}$ to $0.55 \mathrm{~mm}$. Measurements were conducted at a range of Reynolds numbers from 39 to 225 . The effects of the Reynolds number on the heat transfer coefficient and friction factor of the regenerator were assessed. It is worth noting that the test regenerators used in prior studies 1,3 using the single-blow method were stacked with less than 100 wire screens, much less than the 500-600 screens used in a typical regenerator. In the present study, three test regenerators have 560 wire screens. Such a large number of wire screens could increase the fluid flow-through time in the regenerator and the heat transfer coefficient. With both of these effects, adiabatic walls cannot be assumed for the single-blow model. An improve model for the singleblow method was proposed in the present study to determine the heat transfer coefficient of the screen-packed matrix with an $\mathrm{NTU}_{\mathrm{m}}$ value greater than 100 .
Dimensionless time constant of inlet fluid temperature

\section{Superscripts}

* Dimensional variable

\section{Analysis of the improved single-blow model}

In single-blow measurement, a steady gas stream, typically an air stream, is supplied to flow through a regenerator as shown in Figure 1. When the fluid inlet temperature is suddenly increased by turning on a heater installed upstream of the test regenerator, the temperatures of the screen-packed matrix, tube and air flow vary with both time and space. All these temperature histories at particular locations can be predicted from an adequate analytical model by assuming the average heat transfer coefficient between the hot air stream and screen-packed matrix remains constant. Thus, the average coefficient can be determined by matching the predicted and measured exit fluid temperature histories once the time-dependent inlet fluid temperature response is known.

To predict the temperature histories of the screen-packed matrix, tube and air llow, an inproved model to describe the heat transfer system is proposed for the single-blow method. The present model is similar to the one in Liang and Yang ${ }^{7}$ but also includes the heat flow from the boundary of the test heat exchanger (screen-packed matrix in the present study) into the external tube and the JouleThomson expansion in the air stream. The pressure drop through the test screen-packed matrix stacked with hundreds of wire screens is usually greater than $0.1 \mathrm{MPa}$. If the fluid is not an ideal gas, Joule-Thomson expansion occurs when the air stream flows through the screen-packed matrix. To include the effects of both the Joule-Thomson expansion and the heat flux into the tube, additional assumptions other than those in Liang and Yang ${ }^{7}$ are made. These important assumptions are a linear decrease in fluid pressure through the matrix and no radial temperature variation in the tube. Therefore, the dimensionless formulas for the heat transfer system of the single-blow measurements are given by

$$
\frac{\partial T_{\mathrm{f}}}{\partial x}+\operatorname{NTU}_{\mathrm{m}}\left(T_{\mathrm{f}}-T_{\mathrm{m}}\right)+\mathrm{NTU}_{\mathrm{w}}\left(T_{\mathrm{f}}-T_{\mathrm{w}}\right)=\mathrm{JTC}
$$

for the working fluid,

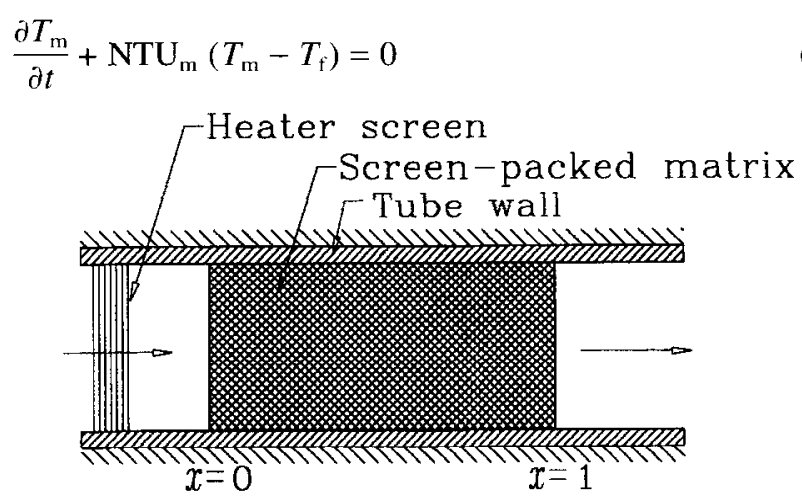

Figure 1 Schematic view of a single-blow measurement 
for the screen-packed matrix and

$\frac{\partial T_{\mathrm{w}}}{\partial t}+R_{\mathrm{tc}} \mathrm{NTU}_{\mathrm{w}}\left(T_{\mathrm{w}}-T_{\mathrm{f}}\right)=0$

for the tube. Equation ( 3 ) is the additional energy equation in the present improved model used to solve the timedependent temperature of the tube at different locations of $x$.

In Equations (1)-(3), the dimensionless variables or parameters are expressed as

$T_{\mathrm{f}}=\frac{T_{\mathrm{f}}^{*}-T_{0}^{*}}{T_{\mathrm{f} \max }^{*}-T_{0}^{*}}, T_{\mathrm{m}}=\frac{T_{\mathrm{m}}^{*}-T_{0}^{*}}{T_{\mathrm{f} \max }^{*}-T_{0}^{*}}, T_{\mathrm{w}}=\frac{T_{\mathrm{w}}^{*}-T_{0}^{*}}{T_{\mathrm{f} \max }^{*}-T_{0}^{*}}, x=\frac{x^{*}}{L}$,

$t=\frac{t^{*}}{t_{\mathrm{sys}}^{*}}, t_{\mathrm{sys}}^{*}=\frac{M_{\mathrm{m}} C_{\mathrm{m}}}{\dot{m}_{\mathrm{f}} C_{p}}, p=\frac{p^{*} \mu_{\mathrm{J}}}{T_{\mathrm{f} \max }^{*}-T_{0}^{*}}, R_{\mathrm{tc}}=\frac{M_{\mathrm{m}} C_{\mathrm{m}}}{M_{\mathrm{w}} C_{\mathrm{w}}}$

$\mathrm{NTU}=\frac{h A_{\mathrm{HT}}}{\dot{m}_{\mathrm{f}} C_{p}}, \mathrm{NTU}_{\mathrm{w}}=\frac{h_{\mathrm{w}} A_{\mathrm{w}}}{\dot{m}_{\mathrm{f}} C_{\mathrm{p}}}, \mathrm{JTC}=\frac{\mathrm{d} p}{\mathrm{~d} x}$

As compared with the model in Liang and $\mathrm{Yang}^{7}$, additional dimensionless groups such as $\mathrm{NTU}_{\mathrm{w}}, \mathrm{JTC}$ and $R_{\mathrm{tc}}$ and an extra variable $T_{\mathrm{w}}$ are included in the present improved model. Equations (1)-(3) are subject to the following initial and boundary conditions:

$t=0, T_{\mathrm{f}}(x)=T_{\mathrm{s}}(x)=T_{\mathrm{w}}(x)=\mathrm{JTC} x$

$x=0, T_{\mathrm{f}}=T_{\mathrm{f}}(t)$ for $t>0$

Numerical predictions of $T_{\mathrm{f}}, T_{\mathrm{m}}$ and $T_{\mathrm{w}}$ are obtained by solving Equations (1)-(6) using a finite-difference method. First, the physical domain of the regenerator is divided using $N$ equally spaced nodes. Except for both end nodes, Equation (1) is discretized on all internal nodes by using a central difference formulation which is second-order accuracy in space. Then, both Equations (2) and (3) are discretized by employing a Crank-Nicolson scheme which is second-order accuracy in time. At each successive time step, the discretized formula on the equally spaced nodes can be rearranged into a single matrix equation, $\mathbf{C X}=\mathbf{D}$. The $(N-1)$ elements of the unknown vector $\mathbf{X}$ represent the temperatures of the fluid on the second node to the $N$ th node at the successive time step. Note that the air temperature on the first node is already known because the boundary condition at the inlet is given by Equation (6). The coefficient matrix of which the elements are related to the known properties of screen-packed matrix, fluid and tube is tri-diagonal. On the right-hand side of the single-matrix equation, the constant vector $\mathbf{D}$ has the $(N-1)$ elements determined from the temperatures of screen-packed matrix, fluid and tube at the present time step. Therefore, the fluid temperatures at the successive time step can be directly solved from the known temperatures of screen-packed matrix, fluid and tube at the present time step. Once the fluid temperatures at the successive time step are known, the temperatures of screen-packed matrix and tube at the successive time step are obtained from the discretized Equations (2) and (3).

If the inlet fluid temperature response is an exponential function, given by

$T_{\mathrm{f}}(t)=1-\exp \left(t /\left(\tau^{*} / t_{\mathrm{sys}}^{*}\right)\right)$ in which $\tau^{*}$ is the dimensional time constant of the measured inlet fluid temperature history, Equations (1)-(6) can be solved analytically by using a Laplace transformation. It has been proved that the analytic and numerical predictions for the exit fluid temperature are in close agreement ${ }^{10}$

If the effects of both the heat flux into the tube wall and the Joule-Thomson expansion were further neglected in the energy Equations (1)-(3), the present numerical results also agree well with the analytic solutions in Liang and Yang ${ }^{7}$.

\section{Experimental apparatus}

In the present study, a transient single-blow technique has been used to measure both the friction loss and heat transfer coefficient of test regenerators. As shown in Figure 2, the single-blow system includes a small air tunnel, a wirescreen heater system, and an automated data acquisition unit. The operating procedure of the present system is similar to that used by Liang and Yang ${ }^{7}$. To cstablish a steady air flow through the test screen-packed matrix, the air flow was supplied by a reciprocating-type compressor. After leaving the regulator, the air flowed through a divergent nozzle, a flow straightener, a wire-screen heater, an upstream convergent adapter, the test section, a downstream convergent adapter, an orifice flow meter and then exited into the atmosphere. The flow rate of dry air flow, measured by the calibrated orifice, was easily varied by adjusting the regulator, connected to the compressor.

Figure 3 shows a schematic view of the test section containing the test screen-packed matrix. There are two OMEGA T-typed thermocouples with a diameter of $0.25 \mathrm{~mm}$ located at the inlet and exit of the test regenerator. Both thermocouples were calibrated against an HP2804 quartz thermometer which has an uncertainty of $0.04^{\circ} \mathrm{C}$. As the steady air flow was established to pass through the test regenerator, the screen heater was suddenly turned on Consequently, the fluid temperatures at both inlet and exit of the screen-packed matrix were measured, digitized and then recorded into the personal computer. Two KYOWA PG-20KU absolute pressure transducers, one upstream and one downstream, were used to measure the pressure drop through the screen-packed matrix at different test conditions. The output voltages from both transducers were amplified five hundred times through the KYOWA CDV 230B amplifiers. Both amplifiers were calibrated using a function generator to assure a linear amplification of andolog signals in the range to be studied.

In the single-blow method, the uncertainty in determining the $\mathrm{NTU}_{\mathrm{m}}$ value decreases with the time constant $\tau$ of the inlet temperature response in Equation (7). Therefore, the single-blow system requires a heater which can heat up the fluid flow in a very short period. A wire-screen heating unit consisting of a pack of four wire-screen heaters and four DC power suppliers was constructed. In order to increase the heat transfer area between wires and the passing air flow, the spacing between each pair of wires was only $1 \mathrm{~mm}$. To minimize the finite heat capacity of the wire, the diameter of the wire is $0.1 \mathrm{~mm}$ with a resistance of $126.2 \Omega \mathrm{m}^{-1}$. For typical runs, the inlet temperature rise in the fluid, $T_{\mathrm{f} \text { max }}^{*}-T_{\mathrm{o}}^{*}$, was about $5-10^{\circ} \mathrm{C}$, depending on the flow rate. The inlet fluid temperature response curve can be fitted with an exponential function, with the time constant of inlet fluid temperature ranged from 0.8 to $0.4 \mathrm{~s}$, decreasing with increase in flow rate. 


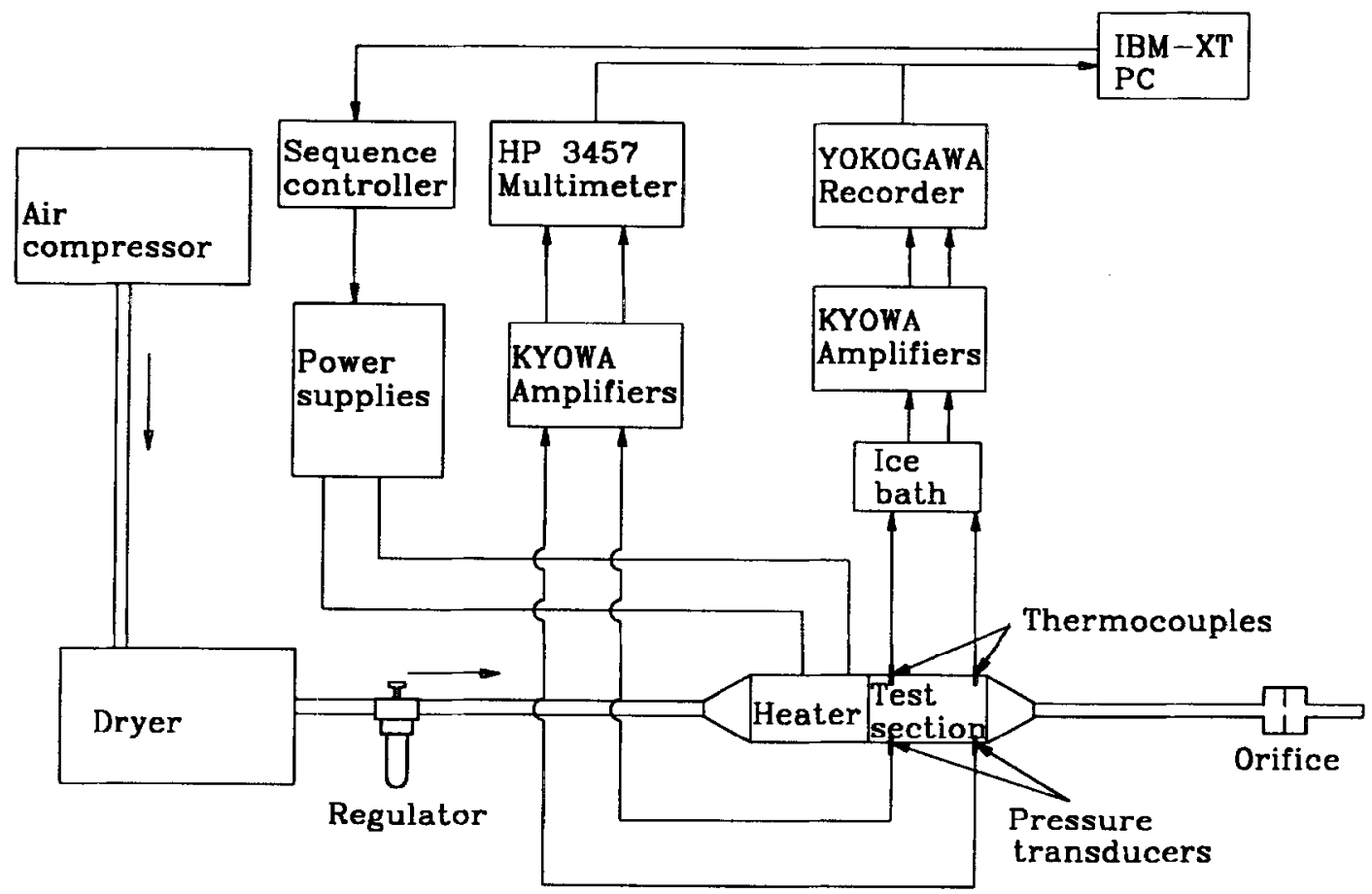

Figure 2 Single-blow measurement and data reduction system

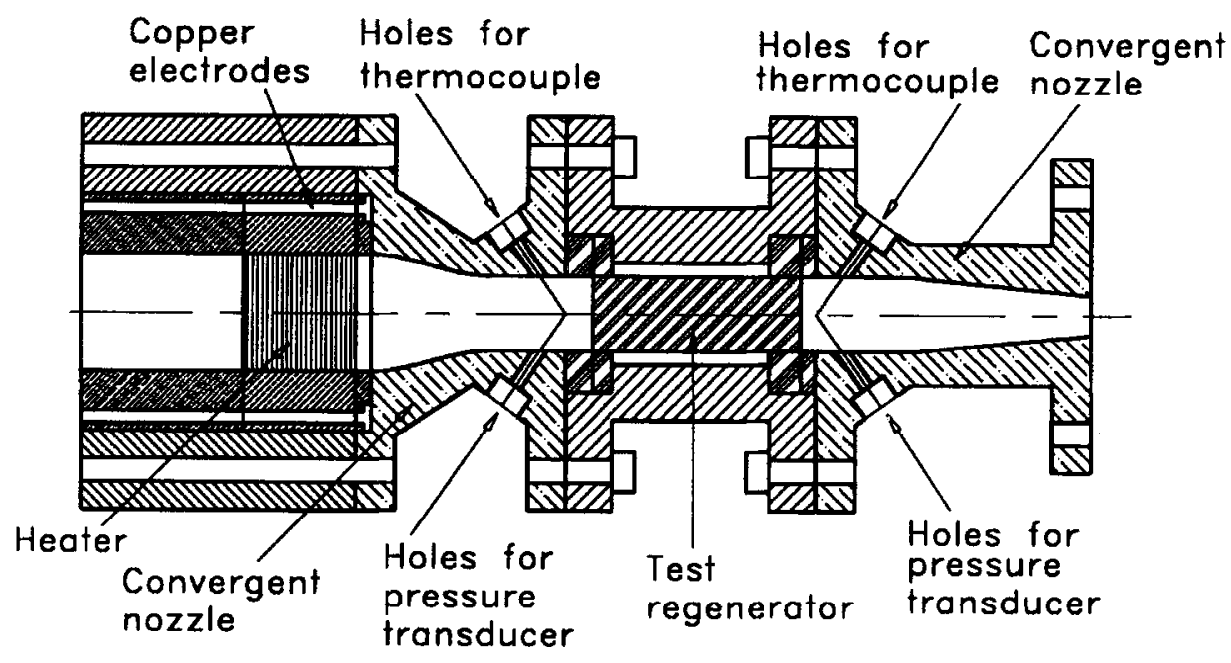

Figure 3 Test section

An automated data acquisition unit was set up to measure the temperature histories and pressure signals at the inlet and exit of the screen-packed matrix. The acquisition unit consisted of an YOKOGAWA 3655E recorder, four KYOWA CDV-230 amplifiers, an IEEE-488 interface bus, a PC computer, and an HP 3457 A multimeter. The temperature and pressure signals were amplified using the KYOWA CDV-230 amplifiers. The temperature and pressure signals were digitized by the YOKOGAWA $3655 \mathrm{E}$ recorder and the HP 3457A multimeter, respectively. The digitized results were immediately transmitted back to the PC computer through the IEEE-488 interface bus. The sampling rate for the temperature measurements was $10 \mathrm{~Hz}$. The volumetric flow rate through the test regenerator was measured by a flange-type orifice which was installed at the end of the test section. The calibration of the orifice was performed in the precision measurement centre of ITRI in Taiwan.

In order to study the effect of wire screen oversizc, three regenerators $\mathrm{A}, \mathrm{B}$ and $\mathrm{C}$ were tested in the present study. Physical properties and dimensions of these regenerators are listed in Table 1, where the definitions of the heat transfer area of the screen-packed matrix, $A_{\mathrm{HT}}$, and the hydraulic diameter of the wire screen, $d_{\mathrm{h}}$, are same as those in the paper by Tanaka et al. ${ }^{5}$. The equations for both parameters are given by

$d_{\mathrm{h}}=\left\{\left(4 \epsilon d_{\mathrm{w}}\right) / \phi(1-\epsilon)\right\}$

$A_{\mathrm{HT}}=\left\{4(1-\epsilon) V_{\mathrm{o}} / d_{\mathrm{w}}\right\}$

where the porosity $\epsilon$ is determined from the bulk density of stainless steel, $\phi$ is a shape factor, $V_{0}$ denotes the volume of the screen-packed matrix and $d_{\mathrm{w}}$ represents the wire diameter. The value of $\phi$ is 4 for a wire screen. For all regenerators, the tubes are made of stainless steel and the regenerator matrices were made of 200 mesh SUS 316 
Table 1 Physical properties and dimensions of test regenerators

\begin{tabular}{|c|c|c|c|}
\hline Regenerator type & A & B & C \\
\hline Wire-screen material & SUS 316 & SUS 316 & SUS 316 \\
\hline External tube material & SUS 316 & SUS 316 & SUS 316 \\
\hline$L(\mathrm{~mm})$ & 60 & 60 & 60 \\
\hline Inner diameter of external tube $(\mathrm{mm})$ & 19.0 & 18.7 & 18.5 \\
\hline Diameter of wire screen $(\mathrm{mm})$ & 19.05 & 19.05 & 19.05 \\
\hline Tube thickness $(\mathrm{mm})$ & 0.28 & 0.43 & 0.53 \\
\hline$V_{0}\left(\mathrm{~mm}^{3}\right)$ & 17011.4 & 16478.8 & 16128.2 \\
\hline Mesh number of wire screen & 200 & 200 & 200 \\
\hline$C_{m}\left(\mathrm{~J} \mathrm{~kg}^{-1} \mathrm{~K}^{-1}\right)$ & 468 & 468 & 468 \\
\hline$d_{w}(\mathrm{~mm})$ & 0.0508 & 0.0508 & 0.0508 \\
\hline Number of wire screen & 560 & 560 & 560 \\
\hline$M_{\mathrm{m}}(\mathrm{g})$ & 38.65 & 38.65 & 38.65 \\
\hline$\epsilon$ & 0.7035 & 0.6939 & 0.6873 \\
\hline$d_{\mathrm{h}}(\mathrm{mm})$ & 0.1205 & 0.1152 & 0.1117 \\
\hline$A_{\mathrm{HT}}\left(\mathrm{cm}^{2}\right)$ & 3971.56 & 3971.56 & 3971.56 \\
\hline$M_{w}(g)$ & 7.662 & 11.675 & 14.316 \\
\hline$C_{\mathrm{w}}\left(\mathrm{J} \mathrm{kg}^{-1} \mathrm{~K}^{-1}\right)$ & 468 & 468 & 468 \\
\hline$R_{\mathrm{tc}}\left(M_{\mathrm{m}} C_{\mathrm{m}} / M_{\mathrm{w}} C_{\mathrm{w}}\right)$ & 5.04 & 3.31 & 2.79 \\
\hline
\end{tabular}

stainless-steel wire screens. The diameter of the circular wire screen was $19.05 \mathrm{~mm}$ for all regenerator matrices. The oversizes in the wire screen were $0.05 \mathrm{~mm}, 0.35 \mathrm{~mm}$ and $0.55 \mathrm{~mm}$ for the regenerators $\mathrm{A}, \mathrm{B}$ and $\mathrm{C}$, respectively. The purpose of stacking the oversize wire screens into the tube was to establish a tight fit between the screen and the tube to prevent leakage through the surrounding screen-packed matrix.

\section{Data reduction procedure}

As described earlier, the evaluation of the heat transfer coefficient for the test regenerators using single-blow measurement was performed to match the predicted and measured exit fluid temperature response curves. Two popular schemes, the maximum-slope ${ }^{\kappa}$ and curve-matching $^{7-9}$ schemes, have been used in prior studies. Detailed descriptions of both matching schemes can be found in the aforementioned studies. It is worth note that the dimensionless maximum slope $S_{\max }$ designates the maximum value of $\mathrm{d} T / \mathrm{d} t$, for the exit fluid temperature response curve. If an exponential rise in the inlet fluid temperature is assumed, analytical solutions of the exit fluid temperature response curve from Equations (1)-(6) can be obtained using a Laplace transformation. As shown in Figure 4 for the case of $\tau=0.1$ and $R_{\mathrm{tc}}=5$, the relationships between $S_{\max }$ and $\mathrm{NTU}_{\mathrm{m}}$ can be then derived from the predicted exit fluid temperature. For a fixed value of $\mathrm{NTU}_{\mathrm{w}}$, a unique relationship between $S_{\max }$ and $\mathrm{NTU}_{\mathrm{m}}$ is observed so the $\mathrm{NTU}_{\mathrm{m}}$ value is then determined from this by matching both measured and predicted $S_{\max }$ values. Note that the singleblow measurement with an assumption of adiabatic boundary conditions is the same as the one with $\mathrm{NTU}_{w}=0$ in the present study.

However, there are two unknowns, $\mathrm{NTU}_{\mathrm{m}}$ and $\mathrm{NTU}_{\mathrm{w}}$, to be determined as the heat flow into the tube wall is included in the present single-blow model. The maximum-slope scheme cannot be uniquely applied in this case because one $S_{\max }$ value would correspond to more than one pair of $\mathrm{NTU}_{\mathrm{m}}$ and $\mathrm{NTU}_{\mathrm{w}}$ values. In Figure 4, four pairs of $\mathrm{NTU}_{\mathrm{m}}$ and $\mathrm{NTU}_{\mathrm{w}}$ values, $\mathrm{NTU}_{\mathrm{m}}=62.19$ and $\mathrm{NTU}_{\mathrm{w}}=0.0$, $\mathrm{NTU}_{\mathrm{m}}=69.67$ and $\mathrm{NTU}_{\mathrm{w}}=0.05, \quad \mathrm{NTU}_{\mathrm{m}}=77.50$ and $\mathrm{NTU}_{\mathrm{w}}-0.1$, and $\mathrm{NTU}_{\mathrm{m}}=93.66$ and $\mathrm{NTU}_{\mathrm{w}}=0.2$, corre-

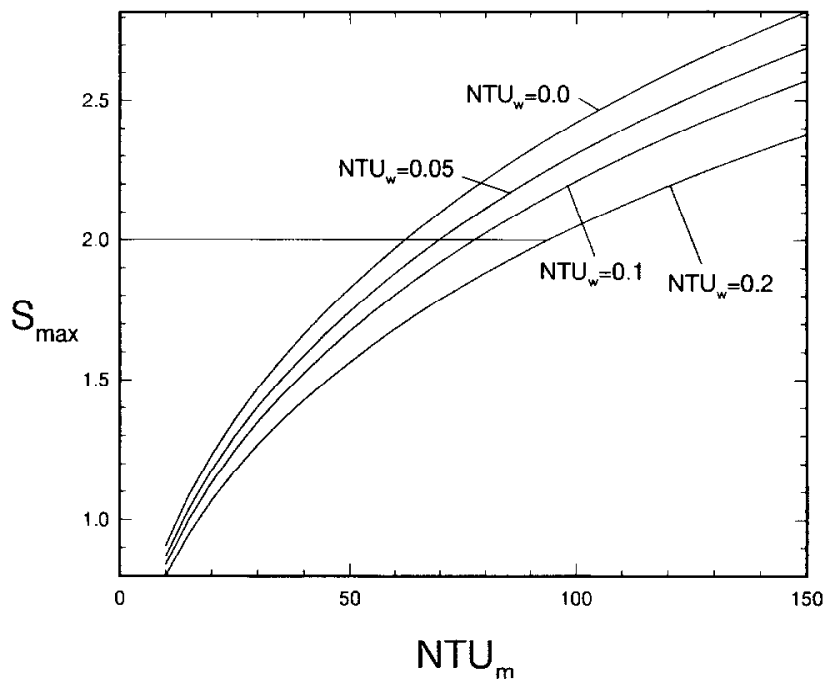

Figure 4 Maximum slope value versus $N_{T U}$ for different values of NTU for $\tau=0.1$ and $R_{\mathrm{tc}}=5$

spond to the same value of $S_{\max }=2.0$. The curve-matching scheme avoids the above problem because a unique relationship still exists between the fluid exit temperature profile and the match of $\mathrm{NTU}_{\mathrm{m}}$ and $\mathrm{NTU}_{\mathrm{w}}$ values. Four exit temperature curves with the same value of $S_{\max }=2.0$ in Figure 4 are shown in Figure 5. These four curves now are distinguishable although they have the same value of $S_{\text {max }}$. The major drawback of the curve-matching scheme is that the uncertainty for the curve-matching scheme is higher than that for the maximum-slope scheme for regenerators with high $\mathrm{NTU}_{\mathrm{m}}$ values ${ }^{10}$. Therefore, a hybridmatch method including both maximum-slope and curvematching schemes was used at the same time to determine $\mathrm{NTU}_{\mathrm{m}}$ and $\mathrm{NTU}_{\mathrm{w}}$ values in the present study. In the evaluation procedure, a pair of values of $\mathrm{NTU}_{\mathrm{m}}$ and $\mathrm{NTU}_{\mathrm{w}}$ are predicted and substituted into the present model to yield an exit fluid temperature profile prediction. This predicted temperature profile and the associated maximum slope $S_{\max }$ are compared with the measured profile and value. If these two sets of profiles and the $S_{\max }$ values match within specified limits, then the $\mathrm{NTU}_{\mathrm{m}}$ and $\mathrm{NTU}_{\mathrm{w}}$ values are determined. If they do not match, $N T U_{m}$ and $N T U_{w}$ values must 


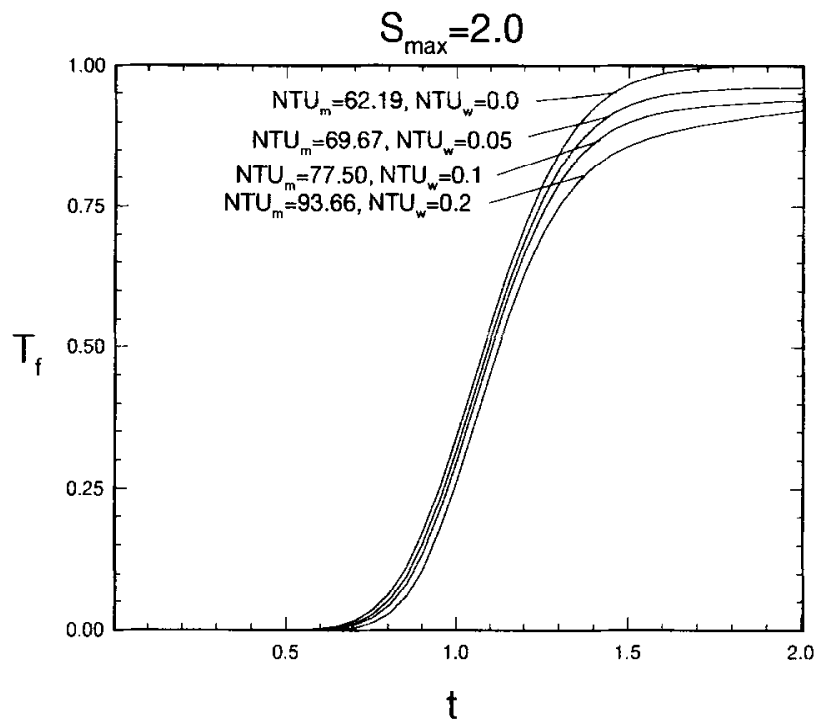

Figure 5 Exit temperature response for different $N T U_{m}$ and NTU ${ }_{w}$ values with $S_{\max }=2.0$ for $\tau=0.1$ and $R_{\mathrm{tc}}=\mathbf{5}$

be adjusted and the process is repeated until correct $\mathrm{NTU}_{\mathrm{m}}$ and $\mathrm{NTU}_{\mathrm{w}}$ values are obtained.

Although there are two unknowns to be simultaneously determined, the hybrid-match procedure will not be too slow to converge because there exists some ratio of the $\mathrm{NTU}_{\mathrm{m}}$ and $\mathrm{NTU}_{\mathrm{w}}$ values. This ratio is usually smaller than the heat transfer area ratio of the tube to the screenpacked matrix.

In the present model, one should be aware that the same predicted exit air temperature can be obtained by exchanging $\mathrm{NTU}_{\mathrm{m}}$ and $\mathrm{NTU}_{\mathrm{w}}$ values at $R_{\mathrm{tc}}=1,0$ because both energy Equations (2) and (3) of the screen-packed matrix and tube then have the same form. When using the hybridmatch method, it is easy to distinguish betwecn the $\mathrm{NTU}_{\mathrm{m}}$ and $\mathrm{NTU}_{\mathrm{w}}$ values because the $\mathrm{NTU}_{\mathrm{m}}$ value is much larger than $\mathrm{NTU}_{\mathrm{m}}$ due to a large heat transfer area ratio between the screen-packed matrix and the tube, approximately several hundreds to unity. The heat transfer coefficient of the screen-packed matrix is then determined from the value of $\mathrm{NTU}_{\mathrm{m}}$ obtained.

After the heat transfer coefficient of screen-packed matrix and the pressure drop through the screen-packed matrix were obtained from the temperature and pressure measurements, the heat transfer and friction loss results were presented in terms of Nusselt number $\mathrm{Nu}$ and friction factor $f$, respectively. Definitions of $\mathrm{Re}, f$ and $\mathrm{Nu}$ are given by

$$
\begin{aligned}
\operatorname{Re} & =\left(\dot{m}_{\mathrm{f}} d_{\mathrm{h}}\right) /\left(\mu A_{\mathrm{f}} \epsilon\right) \\
f & =\frac{2 \triangle p^{*} \rho d_{\mathrm{h}}}{\left(\dot{m}_{\mathrm{f}} / A_{\mathrm{f}} \epsilon\right)^{2} L} \\
N u & =h d_{\mathrm{h}} / k_{\mathrm{f}}
\end{aligned}
$$

\section{Test conditions and error analysis}

In the present study using the single-blow method, the heat transfer and pressure measurements were performed on three regenerators at a range of $\operatorname{Re}$ from 39 to 225 . The oversize in wire screen for these three test regenerators varies from $0.05 \mathrm{~mm}$ to $0.55 \mathrm{~mm}$. To estimate the uncertainties
Table 2 Uncertainty analysis for experimental data

\begin{tabular}{|ll|}
\hline Parameter & Uncertainty $\{\%\}$ \\
\hline$P^{*}$ & 0.38 \\
$T^{*}$ & 0.054 \\
$\rho$ & 0.384 \\
$\dot{m}_{\mathrm{f}}$ & 3.05 \\
$A_{\mathrm{f}}$ & 1.03 \\
$d_{\mathrm{h}}$ & 2.88 \\
$L$ & 0.167 \\
$h$ & 3.93 \\
$A_{\mathrm{HT}}$ & 3.07 \\
$\mathrm{NTU}$ & 2.23 \\
$\mathrm{Re}$ & 4.32 \\
$f$ & 6.63 \\
$\mathrm{Nu}$ & 5.66 \\
\hline
\end{tabular}

in the measured quantities, an uncertainty analysis with a 95\% confidence interval was carried out according to the method described in Kline and McClintock ${ }^{11}$. Based on the error analysis, uncertainties of measured parameters are listed in Table 2. The best estimate of uncertainties in $f$ and $\mathrm{Nu}$ are $6.63 \%$ and $5.66 \%$, respectively.

\section{Results and discussion}

Three regenerators A, B and C in this study were tested. Figure 6 shows the measured inlet and exit air temperatures as well as the predicted exit air temperature curves with three different combinations of $\mathrm{NTU}_{\mathrm{m}}$ and $\mathrm{NTU}_{\mathrm{w}}$ values plotted against time for $\mathrm{Re}=148.56$ for the test regenerator B. In Figure 6, actual measured and predicted exit temperature curves have the same maximum slope value, $S_{\text {max }}=2.55$. The one with $\mathrm{NTU}_{\mathrm{m}}=148.2$ and $\mathrm{NTU}_{\mathrm{w}}=0.13$ is the best match. As mentioned earlier, the relationship between $S_{\max }$ and $\mathrm{NTU}_{\mathrm{m}}$ is unique for a fixed value of $\mathrm{NTU}_{\mathrm{w}}$. Therefore, the hybrid-match method can be used to determine both N'IU $_{m}$ and NTU $_{w}$ values by matching a predicted exit air temperature curve with the actual measured one. From this figure, it is apparent that the $\mathrm{NTU}_{\mathrm{m}}$ value for the actual exit temperature curve $\left(\mathrm{NTU}_{\mathrm{m}}=148.2\right)$ at $S_{\max }=2.55$ is significantly larger than the $\mathrm{NTU}_{\mathrm{m}}$ value

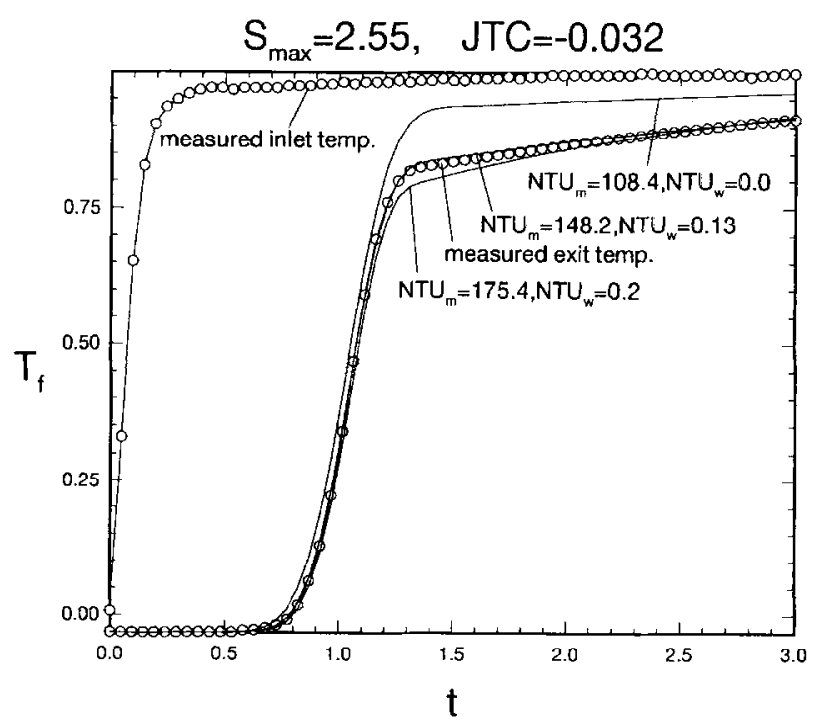

Figure 6 Curve matching between measured and predicted exit fluid temperature histories of regenerator $B$ at $R e=148.56$, $S_{\max }=2.55$ and $\mathrm{JTC}=-0.032$ 
Regenerator thermal performance: P.-H. Chen et al.

Table $3 \mathrm{NTU}_{\mathrm{m}}$ and $\mathrm{NTU}_{\mathrm{w}}$ values of test regenerators $\mathrm{A}, \mathrm{B}$ and $\mathrm{C}\left(R=\mathrm{NTU}_{\mathrm{w}} / \mathrm{NTU}_{\mathrm{m}}\right)$

\begin{tabular}{|c|c|c|c|c|c|c|c|c|c|c|c|}
\hline \multicolumn{4}{|c|}{ Regenerator A } & \multicolumn{4}{|c|}{ Regenerator B } & \multicolumn{4}{|c|}{ Regenerator $\mathrm{C}$} \\
\hline $\operatorname{Re}$ & $\mathrm{NTU}_{\mathrm{m}}$ & $\mathrm{NTU}_{\mathrm{w}}$ & $R \times 10^{3}$ & $\operatorname{Re}$ & $\mathrm{NTU}_{\mathrm{m}}$ & $\mathrm{NTU}_{w}$ & $R \times 10^{3}$ & $\operatorname{Re}$ & $\mathrm{NTU}_{\mathrm{m}}$ & $\mathrm{NTU}_{w}$ & $R \times 10^{3}$ \\
\hline 45.39 & 232.03 & 0.24 & 1.034 & 41.97 & 279.69 & 0.24 & 0.858 & 39.03 & 313.28 & 0.29 & 0.926 \\
\hline 69.80 & 178.89 & 0.17 & 0.950 & 69.57 & 213.28 & 0.21 & 0.985 & 69.06 & 235.94 & 0.22 & 0.932 \\
\hline 93.26 & 157.40 & 0.17 & 1.080 & 93.56 & 178.89 & 0.15 & 0.839 & 89.55 & 192.32 & 0.16 & 0.832 \\
\hline 103.71 & 148.96 & 0.15 & 1.007 & 111.21 & 168.15 & 0.15 & 0.892 & 105.23 & 173.90 & 0.14 & 0.805 \\
\hline 122.17 & 144.35 & 0.15 & 1.039 & 135.58 & 156.25 & 0.14 & 0.896 & 126.96 & 170.06 & 0.15 & 0.882 \\
\hline 138.05 & 143.20 & 0.14 & 0.978 & 148.56 & 148.19 & 0.13 & 0.877 & 148.65 & 162.77 & 0.13 & 0.799 \\
\hline 154.34 & 134.76 & 0.13 & 0.965 & 162.78 & 141.28 & 0.13 & 0.920 & 159.31 & 167.76 & 0.16 & 0.954 \\
\hline 170.09 & 124.39 & 0.11 & 0.884 & 185.85 & 146.65 & 0.13 & 0.886 & 171.48 & 158.55 & 0.13 & 0.820 \\
\hline 189.62 & 118.64 & 0.11 & 0.927 & 206.28 & 128.62 & 0.12 & 0.993 & 182.55 & 151.64 & 0.12 & 0.791 \\
\hline 212.31 & 107.51 & 0.10 & 0.930 & 224.98 & 123.24 & 0.10 & 0.811 & 204.21 & 143.20 & 0.12 & 0.838 \\
\hline & & & & & & & & 216.66 & 132.07 & 0.11 & 0.833 \\
\hline
\end{tabular}

in the case of an adiabatic side wall $\left(\mathrm{NTU}_{\mathrm{m}}=108.4\right)$. Therefore, prior studies assuming an adiabatic side wall underestimate $\mathrm{NTU}_{\mathrm{m}}$ by around $26.8 \%$. Such evidence from the present measured results strongly indicates that the assumption of an adiabatic side wall should not be made when using the single-blow method to determine the thermal performance of test regenerators with high $\mathrm{NTU}_{\mathrm{m}}$ values. Another study using the single-blow method conducted by Mullisen and Loehrke ${ }^{8}$ showed a larger side wall temperature rise for an increase in the $\mathrm{NTU}_{\mathrm{m}}$ value, which also suggests that adiabatic side wall assumption is not valid for test regenerator with high $\mathrm{NTU}_{\mathrm{m}}$ values. Mullisen and Loehrke ${ }^{8}$ did not propose an improved model for solving this problem.

The measured $\mathrm{NTU}_{\mathrm{m}}$ and $\mathrm{NTU}_{\mathrm{w}}$ values at given $\mathrm{Re}$ values are listed in Table 3 . Note that the ratio of $\mathrm{NTU}_{\mathrm{w}}$ to $\mathrm{NTU}_{\mathrm{m}}(R)$ varies slightly with the Reynolds number for each regenerator. The average ratio of $\mathrm{NTU}_{\mathrm{w}}$ to $\mathrm{NTU}_{\mathrm{m}}$ for regenerators $\mathrm{A}, \mathrm{B}$ and $\mathrm{C}$ are $9.79 \times 10^{-4}, 8.90 \times 10^{-1}$ and $8.56 \times 10^{-4}$, respectively. This ratio decreases slightly with an increase of the oversize of the test regenerator, most likely because the heat transfer area between the tube and the fluid decreases with increase in oversize in wire screens.

Figure 7 shows the relationship between $f$ and $\mathrm{Re}$ for runs conducted with varying flow rates. It is apparent that the friction factor decreases with the Reynolds number. At the same Reynolds number, it is expected that regenerator $\mathrm{C}$ has the largest friction factor among the three regener-

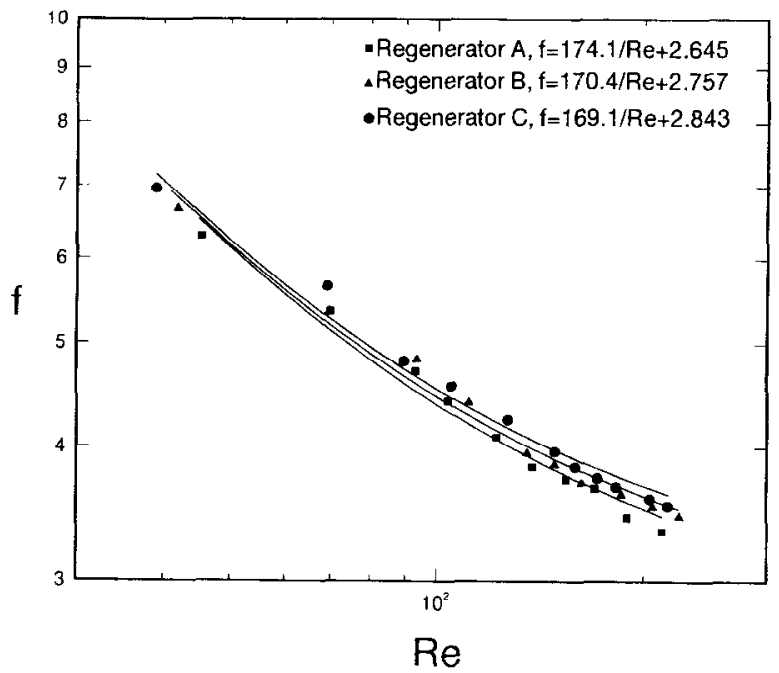

Figure 7 Correlation between $f$ and $R e$ ators because it has the largest oversize in wire screens packed into the tube. Accordingly, the flow leakage through the inner circumference of the tube is reduced with increase in oversize in wire screens. To correlate the measured data of $f$ versus $\mathrm{Re}$ using the least-squares fit method, the empirical correlations for the three regenerators are given by

$f=\frac{174.1}{\operatorname{Re}}+2.645$ for regenerator $\mathrm{A}$

$f=\frac{170.4}{\operatorname{Re}}+2.757$ for regenerator $\mathrm{B}$

$f=\frac{169.1}{\operatorname{Re}}+2.843$ for regenerator $\mathrm{C}$

Figure 8 shows the relationship between $\mathrm{Nu}$ and $\mathrm{Re}$ for the test regenerators. For comparison, experimental data for test regenerators packed with $\mathbf{4 0}$ wire screens obtained from Hamaguchi et $a .^{2}$ are also presented. Various screenpacked regenerator matrices with mesh numbers ranging from 10 to 250 were tested in their study.

As indicated in Figure 8, the heat transfer rate increases with the flow rate. The empirical correlations for Nu versus Re for the three regenerators are given by

$$
\begin{array}{ll}
\mathrm{Nu}=0.483 \mathrm{Re}^{0.548} & \text { for regenerator } \mathrm{A} \\
\mathrm{Nu}=0.549 \mathrm{Re}^{0.353} & \text { for regenerator } \mathrm{B}
\end{array}
$$

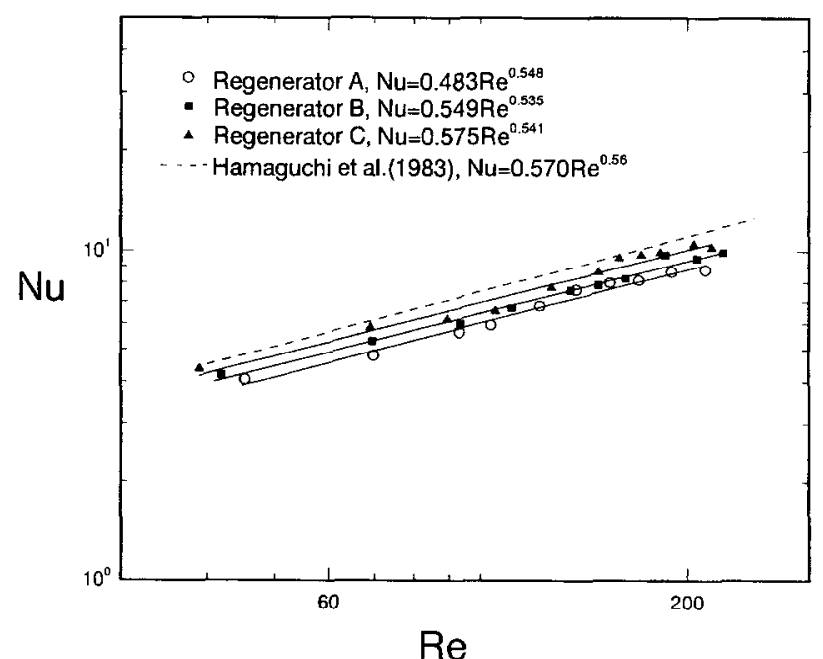

Figure 8 Correlation between $\mathrm{Nu}$ and $\mathrm{Re}$ 
$\mathrm{Nu}=0.575 \mathrm{Re}^{0.541} \quad$ for regenerator $\mathrm{C}$

where the regenerator $C$ has values closest to those of Hamaguchi et al.? The small discrepancy between the measured results of both studies is possibly caused by the difference in the number of wire screens packed into the regenerator matrix, 40 in their study but 560 in the present study. Nevertheless, further studies should be conducted to identify the exact cause of such a discrepancy. The regenerator with the largest oversize in wire screens has the highest heat transfer rate when the Reynolds number is fixed. This is probably due to the fact that an increase in oversize in wire screens reduces the leakage flow between the tube wall and the screen-packed matrix.

\section{Conclusions}

An improved model for the single-blow method was proposed to evaluate the thermal performance of cryocooler regenerators. Effects of heat transfer from the fluid flow into the tube wall and the Joule-Thomson expansion werc included in this model. A hybrid method including both curve-matching and maximum-slope schemes was also proposed in the present study to determine $\mathrm{NTU}_{\mathrm{m}}$ and $\mathrm{NTU}_{\mathrm{w}}$ values.

An experimental system was set up to measure thermal and friction loss characteristics of three regenerators with screen-packed matrices with different oversize values. The Reynolds numbers for the single-blow measurements ranged from 39 to 225 . Empirical correlations of friction factor and Nusselt number versus Reynolds number were presented for all three test regenerators. For the oversize in the screen-packed matrix ranging from $0.05 \mathrm{~mm}$ to $0.55 \mathrm{~mm}$, the regenerator with the largest oversize in the screen-packed matrix had the best thermal performance but the largest friction factor among the three test regenerators. A drop in oversize in the wire screen from $0.55 \mathrm{~mm}$ to $0.05 \mathrm{~mm}$ resulted in a decrease in heat transfer performance of the regenerator matrix on average of $17 \%$.

\section{Acknowledgements}

The partial financial support of this study by the Energy Council under Grant No. $832 Z 6$ is deeply appreciated.

\section{References}

1 Walker, G. and Vasishta, V. Ad Cryo Eng (1971) 16 324-332

2 Hamaguchi, K., Takahachi, S. and Miyabe, H. JSME, Series B (1983) 49 2001-2010 (in Japanese)

3 Tanaka, M. Proc 6th ISEC, Eindhoven (1993) 353-358

4 Jones, J.D. ASME $J$ Eng Gas Turbines and Power (1989) 111 595-600

5 Tanaka, M., Yamashita, I. and Chisaka, F. JSME Int J, Series II (1990) 33 283-289

6 Pucci, P.F., Howard, C.P. and Piersall, C.H. ASME J Eng Power (1967) $8929-40$

7 Liang, C.Y. and Yang, W.J. ASME J Heat Transfer (1975) 97 $16-21$

8 Mullisen, R.S. and Loehrke, R.I. ASME J Heat Transfer (1986) $108370-376$

9 Cai, Z.II., Li, M.L., Wu, Y.W. and Ren, II.S. Int J Heat Mass Transfer (1984) 27 971-978

10 Chen, P.H. and Chang, Z.C. Proc Inst Mech Eng, Part C J Mech Eng $S c i$, in revised

11 Kline, S.J. and McClintock, F.A. Mech Eng (1953) 3-8 